\title{
A MULTI-DIMENSIONAL ANALYTICS PLATFORM TO SUPPORT PLANNING AND DESIGN FOR LIVEABLE AND SUSTAINABLE URBAN ENVIRONMENT
}

\author{
S. Sabri ${ }^{1, *}$, Y. Chen ${ }^{1}$, A. Rajabifard ${ }^{1}$, T. K. Lim $^{2}$, V. Khoo ${ }^{3}$, M. Kalantari ${ }^{1}$ \\ ${ }^{1}$ Centre for Spatial Data Infrastructures and Land Administration, Department of Infrastructure Engineering, The University of \\ Melbourle, 3010 VIC, Parkville, Australia - (soheil.sabri, Yiqun.c, abbas.r, mohsen.kalantari)@unimelb.edu.au \\ 2 Singapore Environment Institute, National Environment Agency, 40 Scotts Road, \#13-00 Environment Building, 228231 \\ Singapore- lim_tian_kuay@nea.gov.sg \\ ${ }^{3}$ Land Survey Division, Singapore Land Authority, 55 Newton Road, \#12-01, 307987 Singapore - victor_khoo@sla.gov.sg
}

Commission VI, WG VI/10

KEY WORDS: 3D Geospatial, BIM, CityGML, Urban Analytics, SDI, Urban Liveability

\begin{abstract}
:
New urban strategies encourage compact city and higher density urban development due to unprecedented city growth and rapid urbanisation. This has led to greater attention to multi-dimensional representation, modelling and analytics of urban settings among urban planners, decision makers, and researchers. Nowadays, urban planning and urban design practitioners and scholars leverage the advancements in computer technology and multi-dimensional visualisation in examining the development scenarios from physical, environmental, social, and economic aspects. However, many urban planners still rely on two-dimensional (2D) land information and urban designers use three-dimensional (3D) graphic-based engines to asses a proposed building or assess the impact of changing development regulations. This limits the decision makers from a holistic approach through integrating the urban systems with other application domains such as transport, environmental, and disaster management to ensure the liveability of cities. This paper describes the design, and development of a multi-dimensional and spatially enabled platform to support liveability planning in Singapore. A Quantitative Urban Environment Simulation Tool (QUEST), developed in Singapore, leveraged 3D mapping data captured under the Singapore Land Authority's (SLA) 3D National Topographic Mapping project. SLA's 3D data including Building Information Model (BIM), CityGML, and other geospatial data (building footprints and land use) were processed and adapted as a service for a series of urban analytics. The paper concludes that the prerequisites for any urban environmental simulation system to be integrated with other application domains are 3D mapping data and a digital urban model, which must be spatially accurate and based on open data standards.
\end{abstract}

\section{INTRODUCTION}

Over the last three decades, rapid urbanisation worldwide led to adopting new urban planning approaches such as compact city development and urban intensification strategies [1]. Higher densities of buildings and populations with mix of land uses and activities, and integrated urban infrastructures are promoted by urban planners and policy makers, particularly in the process of urban redevelopment ensuring the environmental, economic and social sustainability. There are, however, several implications such as environmental (urban heat island), socio-economic (gentrification), and physical (congestion) in this type of development. To understand these implications, reliable data and robust analytical tools are crucial to support data-driven evidence-based planning and policy making. While recent technological innovations and geospatial advancements offer unprecedent opportunities, the processes of impact assessment and decision making remained limited to classic data and modelling tools [2].
Furthermore, urban planners and designers have long been facing challenges imagining the manifestation of planning schemes and the zoning and design controls in urban redevelopment projects [3]. Adding to this challenge, in everyday building development proposals, particularly in complex urban areas, planners spend a considerable amount of energy and time determining whether the proposals meet the minimum requirements according to design regulations. Consequently, one of important requirements for planners and designers to both assess the current urban conditions and foresee the future changes is access to robust toolsets. It is timely and important to develop a customised and scalable series of planning and design tools as the current technologies including computation and geospatial data offer unprecedented capabilities.

However, in many jurisdictions worldwide, where compact city development has become the main planning strategy, urban planners rely on two-dimensional (2D) land information and urban designers use three-dimensional (3D) graphic-based engines (3D Max, Unity3D) to envision a proposed building or

Corresponding author 
assess the impact of changing development regulations. The problem with $2 \mathrm{D}$ data is that while the third-dimension information can be embedded, measuring and analysis of the height, depth, and volume aspects are incomplete. Accordingly, the graphic based 3D data has limited capability in carrying and updating the attribute information. Recent advancements and available data and standards in 3D geospatial format have offered promising opportunities to improve the decision making through evaluation of the potential impact of development proposals, visualising urban design outcomes and allowing users to interpret them from multiple viewpoints [4].

This paper describes the design, and development of a multidimensional and spatially enabled platform to support liveability planning. This platform aimed to support the modelling and simulation requirements of urban planning in Singapore through 3D data analysis, visualisation and integration tools, and a series of customised user interfaces to support modelling and simulation scenarios of urban redevelopment. This paper argues that the prerequisites for any urban environmental simulation system to be integrated with other application domains such as transport, disaster, and building appraisal are 3D mapping data and a digital urban model, which must be spatially accurate and based on open data standards. Hence, the Quantitative Urban Environment Simulation Tool (QUEST) [5], developed in Singapore, leveraged 3D mapping data captured under the Singapore Land Authority's (SLA) 3D National Topographic Mapping project [6,7]. SLA's 3D data including Building Information Model (BIM), CityGML, and other geospatial data (e.g. building footprints, land use, and population) were processed, organised and adapted as a service..

The remaining part of this paper proceeds as follows: In the next section, a brief overview on state-of-the-art in 3D analytics and recent applications of different $3 \mathrm{D}$ data types as well as multi-dimensional platforms in urban planning and design process is provided. Section 3 presents the conceptual design and interrelations of the multi-dimensional platform components. The 3D data types, services, and data integration are also presented in the same section. Two urban analytic tools including urban setting change scenario builder and walkability analysis are explained in section 4. This paper ends with discussion about the implications of multi-dimensional platform in modernisation of urban planning, design and management in section 5. The final section also makes suggestions for improvements and speculating on future directions.

\section{MULTI-DIMENSION GEOSPATIAL TECHNOLOGY IN URBAN PLANNING AND DESIGN}

Studies about multi-dimension geospatial technology in urban planning and design can be categorised in conceptual and practical groups. Sabri et al. [4] conceptualised the integration of three-dimensional (3D) data Models in spatial planning tasks (Figure 1). For instance, they indicated that higher levels of detail City models, suggested by [8], as well as Building Information Model (BIM) can be used for Crime Prevention Through Environmental Design (CPTED), which is an urban design task. The application of BIM in CPTED was later considered in criminology studies as well [9]. Furthermore, in advancement of 3D geospatial technologies the literature suggests their integration with stream data (e.g volunteered geographic information) for measuring subjective (e.g. social construction, place experience) and objective (e.g. physical and functional) aspects of neighbourhood character [2].

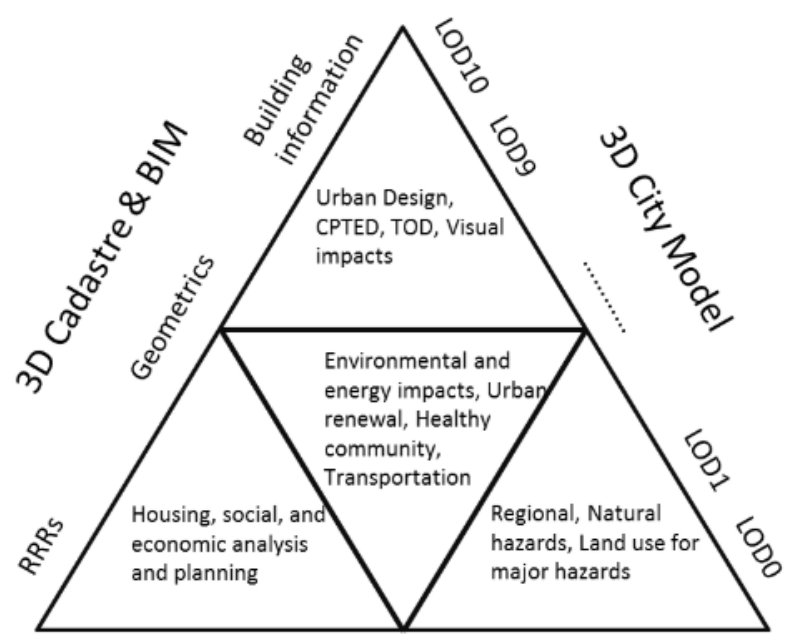

\section{Spatial Planning Tasks}

Figure 1 3D data models and spatial planning tasks. Source:[4]

3D visualisations can improve the mental image of planning controls for planners and stakeholders. For instance, these technologies enable people to assess the effect of buildings on the surroundings (such as view lines) and provide a mechanism for assessment of proposed developments submitted in 3D. Multi-dimensional GIS visualisations also carry analytical components and as such will allow communities to have more effective conversations regarding future developments [3].

Figure 2 illustrates the role of 3D city models in measuring the future scenarios for land use mix development in an urban setting in both horizontal and vertical dimensions [10], as the functional urban aspect.

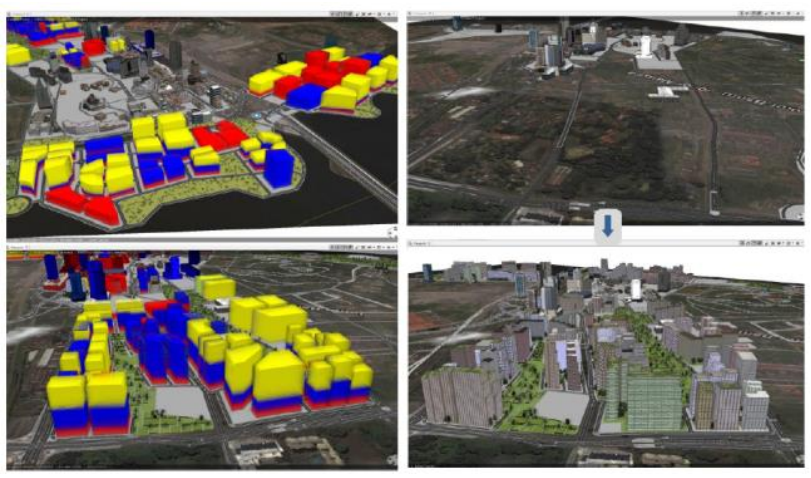

Figure 2 Measuring land use mix development impacts on future urban settings. Sources: $[10,11]$

In terms of modernisation of urban planning and land administration, the literature suggests the capability of 3D land and property information and BIM to be considered in developing new agenda for the future of city management [1214]. In a more specific case, Atazadeh et al., [13] provide a conceptual framework for additional IFC properties to demonstrate the complex property boundaries.

From natural hazards and environmental impact point of view, Amirebrahimi et al., [15] formulated a framework to integrate BIM-GIS data for decision making on flood damage assessment. Their framework brings together the detailed information generated in BIM and modelling, simulation and 
visualisation capabilities of GIS. This conceptual framework can be potentially used in building development assessment activities as part of the statutory planning tasks.

In strategic urban planning, the parametric 3D city models are considered as robust tools in examining the implications of planning rules. For instance, Agius et al., [3] demonstrated the role of parametric 3D city models in urban redevelopment and planning zone changes. Recent literature considered parametric design capabilities through algorithm editor Grasshopper plugins in architectural tools as a useful workflow for urban design process $[16,17]$. These tools provide a robust capability for measuring different urban parameters such as solar radiation, sky view factor (SVF), building setback and height ratio, and floor area ratio (FAR). However, the possibility of integrating these tools with geospatial technologies is not well acknowledged.

In general, Biljecki et al., [18] documented the application of $3 \mathrm{D}$ city models in different urban planning and analytic domains. However, in terms of practical applications of multidimension geospatial data in urban planning tasks, a limited number of literatures is available.

A possible explanation for this limitation is the lack of a digital infrastructure to convert and integrate different 3D data formats for analytical purposes. For instance, planners need to be able to integrate a certain amount of detail from BIM data to be integrated with Digital Elevation Model (DEM) in order to assess the shadow impact or line of sight factors in a development assessment decision making. In other cases, development proposals in CityGML, extruded shape polygon, or even BIM data formats need to be integrated with current city scape through 3D photo-mesh to evaluate the physical impact of future urban developments.

The second explanation is the limited technical skills by planners and decision makers in operating different tools in generating tangible outcomes. This needs an easy to use platform to plug-in analytical tools and access different multidimensional data formats. As such, in this paper a 3D geospatial data integration and analytics infrastructure is presented to overcome above mentioned issues.

\section{CONCEPTUAL DESIGN}

The conceptual design and inter-relationships of the project components are presented in figure 1 . As shown, both data and models can be connected from remote servers after registration to the platform through web APIs. The OGC standards including web feature service (WFS), web map service (WMS), 3D Tiles, web processing service (WPS) are adopted in this platform to link different components together for data accessing, processing, publishing and visualisation.

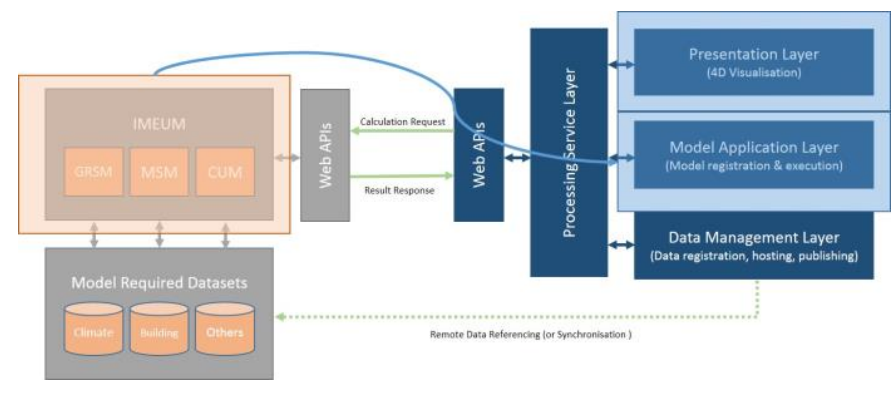

Figure 1: Conceptual design and interrelations of the project components

\subsection{D data types and services}

One of the technical challenges this project aimed to address was to transform and integrate different geospatial formats (e.g., IFC BIM, LOD2 CityGML, 2D vector and raster) into the 3D platform. In order to conduct a scenario-based assessment on built environment changes in urban redevelopment project, different datasets are being used:

- $\quad$ IFC BIM file of the proposed building(s)

- Existing 3D City Model of the area of interest (CityGML profile, according to Ref3DNat recommendations, in LOD2 - or higher if available)

- $\quad$ Roads, tracks, footways, paths

- Buildings footprints

- Cadastre information

- Landscape and vegetation

- Water Features

- Urban Planning Rules

These datasets had been integrated in the platform to conduct modelling and simulation for 3D urban setting scenario building, smart mobility, and flood level impact assessment for the area of interest. While the integration of 2D datasets with CityGML and extruded building footprints in ESRI shapefile format is not an issue, the conversion of BIM data required a considerable amount of time and resources. Next subsection gives an account of data integration process in the 3D platform.

\subsection{D data integration}

Chen et al. [19] detailed the transformation of Building Information Model in the Industry Foundation Classes (IFC) data formats to 3D Ttiles in a Cesium environment to support the city-scale 3D building development. This study uses the same approach as the four key steps suggested in [19] ensuring the attributes of each property in IFC file retains in the conversion process.

Integration of different 3D data types (e.g. IFC, CityGML, Shapefiles) with QUEST outputs (e.g. Thermal Comfort Index) was conducted in the platform (See Figure 2). This integration followed an overall architecture, which was developed for more datasets to be integrated into the platform in the future (e.g. live environment sensor data). 

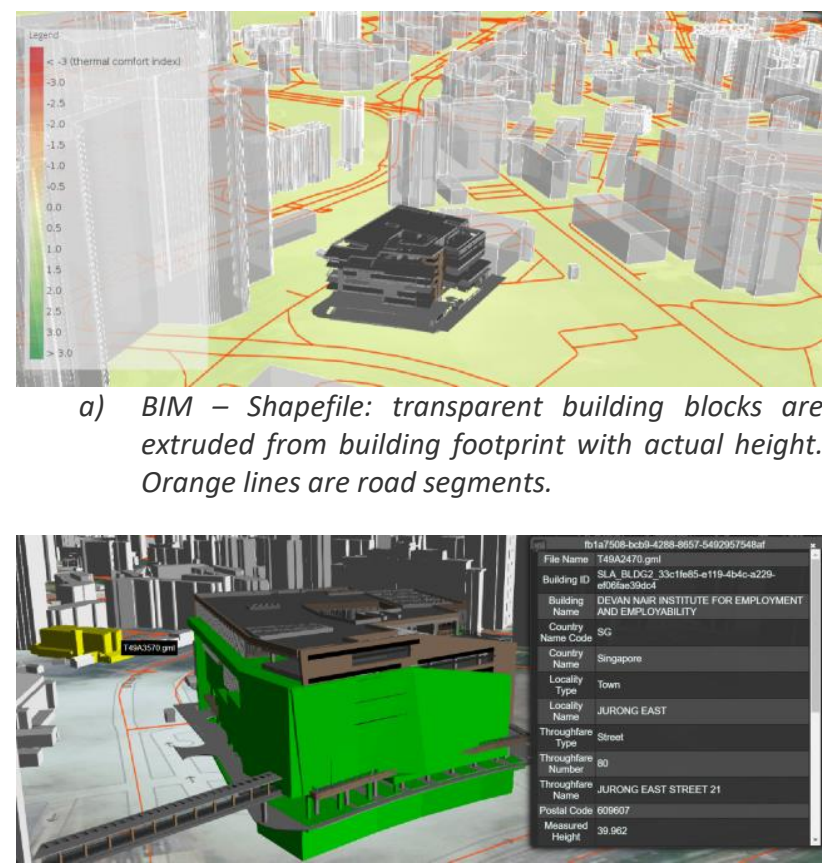

b) BIM - CityGML: details of the BIM data will appear when zooming in; CityGML data is also converted into $3 D$ Tiles and can be queried.

Figure 2: BIM- Shapefile-CityGML and QUEST output data integration in the Multi-dimensional platform

\section{URBAN ANALYTICS TOOLS}

\subsection{D Urban Setting Scenario Builder}

As the first phase, QUEST that was previously implemented in a proprietary GIS software, transferred into R code to be used in this 3D geospatial platform. The second phase was built on the results of this tool, which referred to smart mobility. The second tool was called the walkability analysis and developed based on the connectivity of road networks, as well as on the built (e.g. points of interest and attractiveness of destinations) and natural environment (e.g. temperature, vegetation) aspects of urban areas. Finally, the third phase was a flood level impact assessment. Along with the results of flood modelling, the BIM was used to simulate and assess the impact of flood over different timeframes.

Figure 3 illustrates the configuring QUEST Model user interface, in which a number of land use types (e.g. greenery, road, and waterbodies), as well as building attributes (e.g. height, orientation, scale) can be edited. The modified data will then be passed into the QUEST model for calculation. With this capability, planners can modify urban settings for various design scenarios and evaluate their environment impacts.

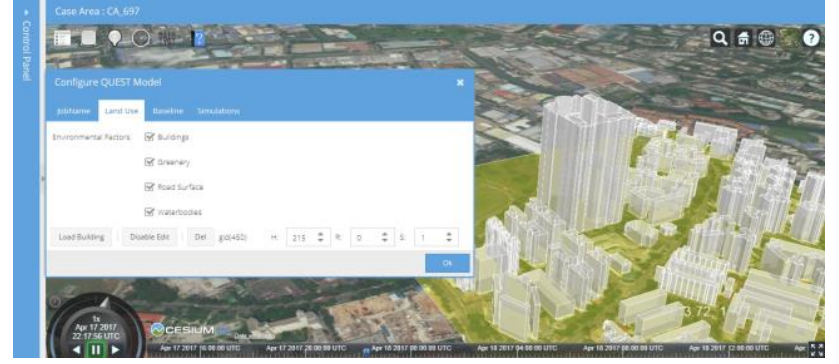

Figure 3: The user interface for QUEST Model configuration

In this tool, two options of dry day and wet day were considered to generate the raster outputs for maximum, minimum and average temperatures. Depending on data availability, this tool can be extended to generate wind, thermal comfort, heat stress risk, and Computational Fluid Dynamics (CFD) results in the future. Ultimately, the feasibility and applicability of the 3D data models in this platform have been evaluated from three perspectives:

- 3D data conversion and visualisation

- Developing 3D Modelling and Simulation services for decision making

- 3D data storage and query

This project highlighted the potential for developing a functional open GIS 3D platform for scenario-based modelling and simulation to support urban planning and design.

\subsection{Walkability Tool}

One of scenario-based modelling and simulation applications in urban planning is walkability analysis. It is important for planners to understand the impact of built environment on the human's perception of walkability. Given that 3D city models will provide reliable parameters for modelling and simulation of walkability, this application was developed in the $3 \mathrm{D}$ platform to show the significant role of 3D data in modelling, simulation, and visualisation for evidence-based planning. Figure 4 shows the walkability tool developed for a case area in Singapore, called East-Jurong MRT station area. The tool is based on the agent modelling and simulation approach, which includes three modules including "The route choice and map navigation module", "The attention-based exploratory movement module", and "The agent-based individual movement module".

In the first module, three parameters of impulse stops, shortest distance, and shortest time considered. For the impulse stops, urban features such as windows and facades are important to be considered.

The second module, "The attention-based exploratory movement module", uses a utility maximisation method for examining the perceptions of pedestrians on their environment. The attractiveness of attractors, distance to attractors, and visibility of attractors are three variables that can be considered in this module. 


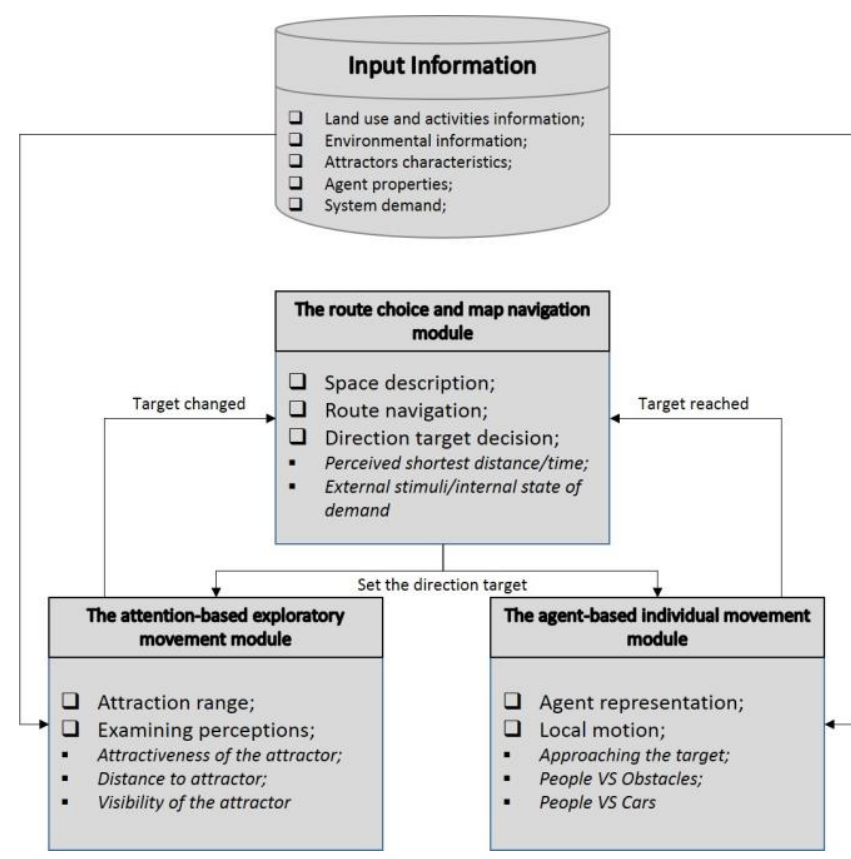

Figure 4: Conceptual Model for outdoor walkability model

The third module, "The agent-based individual movement module", considers the interaction of agent-environment, which can be determined using built environment data, such as physical obstacles and urban furniture. In addition, the QUEST outputs, including sky view factor, tree canopy shading, and building shading, are important parameters to be considered. Other QUEST model outputs, such as minimum and maximum temperature, thermal comfort index, and wind speed/direction are also important for this module. Figure 5 is a snapshot of the walkability model using temperature outputs of QUEST with different agent simulation settings.

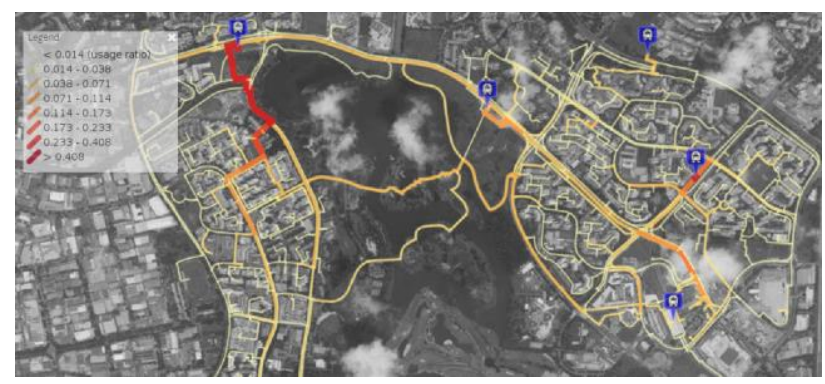

a) road usage with $15 \%$ probability of one extra attraction visit and $25 \%$ travel population

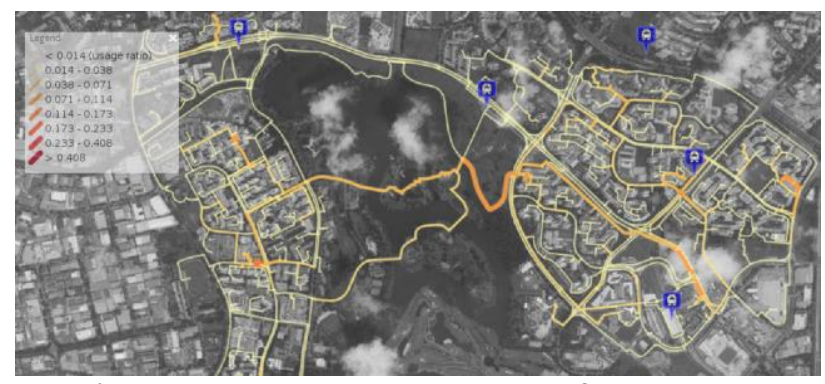

b) road usage with $10 \%$ probability of one extra attraction visit and $20 \%$ travel population

Figure 5: Outdoor walkability simulation using QUEST outputs

\section{DISCUSSION AND CONCLUSION}

This paper set to explain the importance of 3D geospatial platform for planning purposes and argued that the lack of technical skills and different data formats can be considered as challenges for urban planners in using 3D data and integrating with other data types. As such, this paper suggested a 3D geospatial platform that uses OGC standards for geospatial data accessing, processing, publishing and visualisation.

Two built-in tools had also been developed for the platform to test the usability of system. By using the 3D urban setting scenario builder, planners can quickly load physical urban setting datasets (e.g., building footprints, road network, greeneries, water bodies, etc.) and apply modifications to test the environmental impacts of various planning scenarios by feeding these modified data to QUEST. The developed walkability tool further makes use of the QUEST outputs as environmental factors and runs agent-based simulation mimicking people's walk behaviours and characteristics (e.g., environmental related travel preferences, probability of extra attraction visit, origin-destination pair assignment, travel population demographics, etc.). This tool offers the planners with an intuitive viewpoint of how urban planning decisions can directly exert impacts on people's daily live.

As a proof of concept, this work explored and identified different planning tasks that can be conducted using 3D data efficiently. Given the capability of this platform for digital 3D representation of urban environment, it has great potentials to be expanded to support more urban planning analytics and visualisations. As such, this platform offers an opportunity for spatially accurate digital twining of urban areas to integrate the urban environmental simulation system with other application domains such as transport, social behaviour, and disaster management.

\section{ACKNOWLEDGEMENTS (OPTIONAL)}

The authors wish to thank members of the staff at the Singapore Land Authority (SLA), the National Environment Agency (NEA) and the Urban Redevelopment Authority (URA) for the support of this work. Lim Tian Kuay also wish to thank Mr. Ronnie Tay (former CEO, NEA), Mr. Richard Hoo (former Deputy CEO, URA), Prof. Raj Thampuran (A*STAR) and Dr. Vijay Tallapragada (NOAA's NCEP/EMC) for their support and encouragement.

\section{REFERENCES}

1. Burton, E.; Jenks, M.; Williams, K. The Compact City: A Sustainable Urban Form?; Second Edi.; Taylor \& Francis, 2005; ISBN 0-419-21300-7.

2. Sabri, S.; Rajabifard, A.; Ho, S.; Amirebrahimi, S.; Bishop, I. Leveraging VGI Integrated with 3D Spatial Technology to Support Urban Intensification in Melbourne, Australia. Urban Plan. 2016, 1, 32.

3. Agius, T.; Sabri, S.; Kalantari, M. Three-Dimensional Rule-Based City Modelling to Support Urban Redevelopment Process. ISPRS Int. J. GeoInformation 2018, 7, 413.

4. Sabri, S.; Pettit, C.J.; Kalantari, M.; Rajabifard, A.; White, M.; Lade, O.; Ngo, T. What are Essential requirements in Planning for Future Cities using Open 
Data Infrastructures and 3D Data Models? In Proceedings of the 14th Computers in Urban Planning and Urban Management (CUPUM2015); MIT: Boston, MA, 2015; pp. 314-1-314-17.

5. Lim, T.K.; Ignatius, M.; Miguel, M.; Wong, N.H.; Juang, H.-M.H. Multi-scale urban system modeling for sustainable planning and design. Energy Build. 2017, $157,78-91$

6. Soon, K.H.; Thompson, R.; Khoo, V. Semantics-based Fusion for CityGML and 3D LandXML. In Proceedings of the 4th International Workshop on 3D Cadastres,; Dubai, United Arab Emirates, 2014; pp. 323-338.

7. Soon, K.H.; Khoo, V.H.S. CITYGML MODELLING FOR SINGAPORE 3D NATIONAL MAPPING. ISPRS - Int. Arch. Photogramm. Remote Sens. Spat. Inf. Sci. 2017, XLII-4/W7, 37-42.

8. Biljecki, F.; Ledoux, H.; Stoter, J.; Zhao, J. Formalisation of the level of detail in 3D city modelling. Comput. Environ. Urban Syst. 2014, 48, 115 .

9. Cozens, P.; McLeod, S.; Matthews, J. Visual representations in crime prevention: exploring the use of building information modelling (BIM) to investigate burglary and crime prevention through environmental design (CPTED). Crime Prev. Community Saf. 2018, $20,63-83$.

10. Sabri, S.; Ho, S.; Rajabifard, A. Implementing the "20minute neighbourhood": Leveraging New Spatial Data and Technologies to Support Planning for a Sustainable Metropolitan Melbourne. In Healthy Future Cities; Sun Sheng, H., Wenqi, L., Eds.; China Architecture and Building Press: Melbourne, VIC, 2018; pp. 502-517 ISBN 978-7-112-20762-6.

11. Ahmed, A.; Sabri, S. Integrating GeoDesign and Conventional Spatial Analysis Methods in Evaluating Compact City Development. In Proceedings of the International Conference on Sustainable Urban Design for Livable Cities (SUDLiC); Kuala Lumpur, 2014; pp. 276-286.

12. Sabri, S.; Rajabifard, A.; Ho, S.; Namazi-Rad, M.-R.; Pettit, C. IEEE T\&S. December 2015, pp. 33-36.

13. Atazadeh, B. Building information modelling for urban land administration, 2017.

14. Olfat, H.; Shojaei, D.; Briffa, M.; Maley, S.; Rajabifard, A. Strategic Actions for Increasing the Submission of Digital Cadastral Data by the Surveying Industry Based on Lessons Learned from Victoria, Australia. ISPRS Int. J. Geo-Information 2018, 7.

15. Amirebrahimi, S.; Rajabifard, A.; Mendis, P.; Ngo, T.; Sabri, S. A Planning Decision Support Tool for Evaluation and 3D Visualisation of Building Risk in Flood Prone Areas. In Proceedings of the FIG Working Week 2016 - Recover from Disaster; FIG: Christchurch, New Zealand, 2016.

16. Costanzo, V.; Yao, R.; Essah, E.; Shao, L.; Shahrestani, M.; Oliveira, A.C.; Araz, M.; Hepbasli, A.; Biyik, E. A method of strategic evaluation of energy performance of Building Integrated Photovoltaic in the urban context. J. Clean. Prod. 2018, 184, 82-91.

17. Naboni, E.; Natanian, J.; Brizzi, G.; Florio, P.; Chokhachian, A.; Galanos, T.; Rastogi, P. A digital workflow to quantify regenerative urban design in the context of a changing climate. Renew. Sustain. Energy
Rev. 2019, 113, 109255.

18. Biljecki, F.; Stoter, J.; Ledoux, H.; Zlatanova, S.; Çöltekin, A. Applications of 3D City Models: State of the Art Review. ISPRS Int. J. Geo-Information 2015, 4, 2842-2889.

19. Chen, Y.; Shooraj, E.; Rajabifard, A.; Sabri, S. From IFC to 3D Tiles: An Integrated Open-Source Solution for Visualising BIMs on Cesium. ISPRS Int. J. GeoInformation 2018, 7, 393. 